\title{
SIGNIFICACIÓN Y SENTIDO DEL PRAGMATISMO NORTEAMERICANQO
}

Sumario: 1. Génesis del pragmatismo en Charles S. Peirce. 2. La filosofia de Charles S. Peirce. 3. El liderato de William James. 4. El pragmatismo de William James. 5. Empirismo radical y fe religiosa en William James. 6. La decisiva impronta de John Dewey. 7. El instrumentalismo y la cosmovisión de John Dewey. 8. Crítica al pragmatismo norteamericano.

\section{Génesis del pragmatismo en Charles S. Peirce.}

Hoy en día Estados Unidos está dominado, casi totalmente, por la co rriente analítica y lingüistica que ha dado en llamarse neopositivismo lógico. También la fenomenología cuenta con no escasos adeptos y con cierta vigencia entre los filósofos de cátedra. No obstante, el periodo más característico y creativo de la filosofía norteamericana está constituido por el pragmatismo. $Y$ hay quienes esperan que los filósofos contemporáneos reemprendan la tarea más genuinamente estadounidense. Porque dentro y fuera de Estados Unidos se ha considerado al pragmatismo como la filosofía "más claramente norteamericana en sus perfiles". Si la posición social es obra del individuo, y no de sus antepasados, la continuidad de la vida práctica e intelectual -interpenetración de práctica y teoría - se expresa filosóficamente en el pragmatismo. La cultura que ha servidọ de alimento a los filósofos norteamericanos es pragmática. Indicios de la actitud pragmática los encontramos en Jonathan Edwards, Ralph Waldo Emerson y Josiah Royce. Fuera de Estados Unidos, el pragmatismo ha encontrado muy poco apoyo. $Y$ aunque descienda del empirismo británico, es lo cierto que el pragmatismo como escuela se gesta y se desarrolla en Estados Unidos.

Charles Sanders Peirce, William James, George Herbert Mead y John Dewey son los cuatro dioses mayores - si se me permite la expresión- del pragmatismo norteamericano. Peirce es el primero que ofrece la idea-directriz del pragmatismo, pero James es quien populariza el nombre. A los pragmatistas les importa explicar el puesto del pensamiento y del conocimiento en el mundo. El pensamiento es activo. Las realidades se constituyen como tales cuando son conocidas. Los hechos se reconstituyen en la dirección de un valor. La realidad incluye el hecho físico y el hecho mental. El conocimiento es instrumento en el proceso de cambio de una realidad insatisfacto ria a una realidad satisfactoria o menos insatisfactoria. La prueba de la verdad de una teoría reposa en el examen de sus consecuencias. La vida de la educación y la vida de la ley no ha sido la lógica: ha sido la experiencia. 
El pragmatismo se presenta como "un método para reconstruir nuestro pen. samiento y de ese modo recuperar la filosofía", apunta Joseph L. Blau.

Charles S. Peirce (1839-1914), calificado por William James como el pensador norteamericano más neto y puro de su tiempo, es un investigador universal, polifacético, sistemático. Lo mismo trabajaba sobre metafísica, matemática, lógica y religión, que sobre química, óptica, geodesia, psicología, telepatía, criminología y egiptología. Tradujo del latín y del alemán. Se ocupó de la pronunciación del griego clásico y del inglés antiguo. Fue siempre un pionero. Tenía el afán -casi manía- de la precisión. Bertrand Russell decia que Peirce era un volcán que vomitaba masas ingentes de lava, de las cuales podía extraerse cantidad de oro puro. Tras innumerables fracasos, murió solo, sin amigos y sin escuela. Escribía a razón de dos mil palabras diarias. Y sin embargo, sólo dos libros escribió en su vida de largo, acendrado esfuerzo. De esos dos libros, sólo logró publicar uno. Nunca pudo o nunca quiso ingresar a la cátedra universitaria. Su esposa, una joven y distinguida dama de Nueva Inglaterra, se separó de él y pidió el divorcio. A Peirce le faltó, desde entonces, fortaleza y tesitura moral. Pero no careció de genialidades y de conciencia de su talento. Él mismo se comparaba - sin mucha modestia por cierta con Leibniz, el gran genio enciclopédico alemán. Charles S. Peirce no interesó jamás a la masa. Era un pensador para inteligencias privilegiadas. Se oponía, además, a la divinización de los negocios -que seca la corriente en los grandes sentimientos- y al espíritu de claustro. Pensaba, muy a la alemana, que el profesor universitario era un investigador que enseña a investigar. $Y$ la universidad está para crear inventores y no ganadores de dinero. Enemigo de reuniones, se impuso voluntariamente una soledad difícilmente soportable. Este hombre solitario, singular, difícil, dio carta de ciudadanía al pragmatismo con su ensayo publicado en 1878, Cómo aclarar nuestras ideas. Más tarde se distanció del vocablo pragmatismo, inventando uno nuevo para designar a su misma criatura: pragmaticismo. $\mathbf{Y}$ es que no quería seguir con el nombre, cuando se había cambiado lo nombrado.

Más que la luz de la razón natural, Peirce recomendaba el experimento. En vez de la duda total en el pensar — como la postulada por Descartes-, proponía "la duda concreta sobre algo concreto por una razón concreta". De la creencia se marcha a la duda razonable, para llegar a una nueva creencia que genera otra nueva duda. Este procedimienta - lo advierte el propio Charles S. Peirce - no tiene nada que ver con la logica de Hegel. Toda teoría es provisional. El experimento es el sucesor del enlightemment y de la razón pura. Es preciso hacer evidentes las representaciones y los conceptos. El experimento es una técnica científicamente refinada del comprobar. "Todo

1 Joseph L. Bleu, Filósofos y escuelas filosóficas en los Estados Unidos de Norteamérica, Editorial Reverté, S. A., México, Barcelona, Buenos Aires, p. 277: 
lo que nosotros sabemos sobre un objeto es lo que sabemos sobre sus efectos." En el experimento se perciben esos efectos. "Lo que Peirce quería decir cuando hablaba de experimentación era precisamente esto: una acción experimental, a la cual ha de someterse una idea —escribe Ludwig Marcuse - si quiere adquirir su legitimación." "¿Cuál es el sentido y la significación de un pensamiento? - se preguntaba Peirce. Y contesta: 'la forma de actuar' que él provoca." 2 Aquellos malentendidos que tanto le atormentaron más tarde, toman su pie en aquella frase suya: "El valor de un concepto se halla pura y exclusivamente en su significación para la vida práctica". Su complejo antimetafísico le llevó a la pretensión de reducir la filosofía a una serie de preguntas que se pueden someter a observación desde el punto de vista de las ciencias exactas. No pudo comprender que aunque la ciencia no tuviera nada que ofrecer como contestación a las preguntas, las preguntas no por eso perdían su importancia, su enjundia. No podemos desterrar del pensamiento lo que la ciencia no puede contestar.

"Mi lenguaje es el compendio de mi ser", decía Peirce. Y trazaba un sistema de diagramas para expresar con exactitud cualquier pensamiento. El lógico Peirce deja de ser un lógico exclusivista y se introduce en los terrenos de la moral y de la teología. El individuo debe resolverse en la humanidad conocida o en la que está por conocerse. Si fuéramos inmortales sobrevendría la disolución y la desesperanza. Por fortuna somos mortales. "La lógica exige 'imperiosamente' que limitemos nuestros intereses, incluso frente al más allá de nuestro vivir geológico, en bien de la sociedad y de la humanidad." Se opuso a la teología negativa y formuló sus argumentos para demostrar la existencia de Dios. "Lo mismo que uno queda impresionado por el largo trato con un super-hombre o con una gran obra, por ejemplo, la de Aristóteles, así le impresiona a uno el trato íntimo y prolongado con el universo psicofísico." ¿De dónde iba a venir la idea de Dios de no ser de la experiencia directa? El instinto garantiza la certeza de una vida futura y de un Dios incomprensible. "Abrid los ojos -exclamaba Peirce-, abrid el corazón que también es un órgano de percepción y percibiréis a Dios." $\mathrm{Y}$ hasta llegó a decir: "Las vivencias instintivas que nos proporciona la fe son más de fiar que los resultados en la ciencia." Charles Sanders Peirce había sobrepasado, en este estadio, su propio método pragmatista. Y yo no se lo tomo a mal.

\section{La filosofia de Charles S. Peirce}

El pragmatismo es, además de una tendencia temperamental, un conjunto de respuestas técnicas a un grupo de preguntas gnoseológicas. ¿Qué es una idea? Los pragmatistas contestan diciendo lo que una idea hace, nunca lo que

2 L. Marcuse, Filosofia americana, Ed. Guadarrama, Madrid, p. 84. 
es. Las ideas funcionan dentro de la vida como plan de acción en una situación particular. Se miden por el buen éxito.

Charles S. Peirce, inventor incurable de términos nuevos -a menudo bárbaros-, acometía sus serias investigaciones con método mitad severo y mitad irónico. En una época en que el estudio de la lógica, más allá de los niveles elementales, era sumamente raro, Charles Sanders Peirce, precursor de la lógica simbólica, fue un lógico superior y original. Me parece que todavía no ha recibido, a escala mundial, el reconocimiento que merece. Personalmente le tengo por el filósofo más genial de los Estados Unidos. Pensaba que el universo forma hábitos, generaliza y se torna paulatinamente más ordenado. La vida transcurre en pautas de orden. La mente se acrecienta por la generalización de ideas. "Todos los procesos vitales propenden a facilitarse en la repetición." No reaccionamos ante el hecho particular, sino ante sus probables consecuencias. Las ideas en acción son creencias. $Y$ las creencias son planes de acción. El pragmatismo conduce a solucionar el problema del significado. Pero el significado se interpreta en términos de conducta, no de sensación. Debemos "considerar qué efectos, que concebiblemente podría tener sentidos prácticos, concebimos que tenga el objeto de nuestra concepción. Luego nuestra concepción de esos efectos es el todo de nuestra concepción del objeto". ${ }^{3}$ Si un problema no es soluble, no es problema porque no tiene significado. Para definir una palabra significativamente, se precisa describir las condiciones experimentales que le permitirán a cualquiera descubrir en su experiencia el objeto al cual se refiere el término. El significado de una aseveración es la suma de sus consecuencias verificables. "La significación racional de una palabra u otra expresión está exclusivamente en su nelación concebible con el rumbo de la vida." " Esto quiere decir que el significado racional de toda proposición está en lo futuro.

"La función cabal del pensamiento es producir hábitos de acción." 6 La creencia, a diferencia de la duda, está asociada con la acción. La indagación fija la creencia. En la interacción de creencias y opiniones se utiliza el método de la tenacidad individual, el método de autoridad, el método de la discusión y el método de la ciencia. Este último método es el único digno de seguirse. Las creencias son verdaderas en la medida en que esté acorde una comunidad infinita de sabios de laboratorio. Tenemos que decidir si es útil someter nuestras ideas a la comunidad de laboratorio. Inducción y deducción no conducen a ideas nuevas. En cambio la abducción, insinuación de una posibilidad, es una hipótesis que une nuestras observaciones. La insinuación abductiva nos llega como un resplandor instantáneo.

3 Charles S. Peirce (Justus Buchler, ed.), The Philosophy of Peirce, Selected Writings, Harcourt, Brace and Co., 1940, p. \$1.

4 Ibid., p. 252.

5 Ibid., p. 30. 
Es un acto de discermimiento. La hipótesis abducida no suministra garantía alguna de certeza. La conclusión insinúa algo que no hemos observado directamente. En la abducción se entra por desesperación pragmática y se justifica por ser la única esperanza posible de regular racionalmente nuestra conducta futura.

"The real is that which is not whatever we happen to think it, but is unaffected by what we may think of it", asegura Charles S. Peirce. ${ }^{\text {B }}$ Sólo que Peirce habla de la realidad como lo que una comunidad de investigadores está destinada a descubrir con método apropiado. Trataba de ser realista, idealista y pragmatista a un tiempo. "The reality of things consists in their persistent forcing themselves upon our recognition." " Mientras lo real tiene el status del hecho (cosa, idea, sentimiento), la realidad no puede ser asida aparte de una teoria. "The real is the idea in which the community ultimately settles down." 8 La creencia u opinión es un objetivo del inquirir. Una seria inquisición gobernada por la forma del razonamiento sintético, a cargo de la comunidad de investigadores converge, paulatinamente, a la verdad en una larga carrera. El modo de la posibilidad real es el supuesto.

Las proposiciones de Peirce se han convertido en tema de controversia para varias generaciones. ¿Puede ser establecida inductivamente la validez del conocimiento como un problema científico? ¿Está basada la verificación experimental en la fe en un acuerdo circunstancial entre los observadores? ¿Acaso los universales finalmente sostenidos por la comunidad de cognoscentes constituyen la realidad y la verdad? ¿Es posible revivir el realismo mediante la lógica matemática? ¿Pueden la filosofía y las matemáticas aprestarse a la tarea práctica de probar la realidad de la comunidad? Estas cuestiones fueron objeto de prolongadas discusiones en el "Metaphysical Club" integrado por Charles Sanders Peirce, William James, el juez Oliver Wendell Holmes, John Fiske, Chaunoey Wright, el abogado Nicholas St. John Green y Frank Abbott. Allá por 1870, este grupo se reunía con frecuencia, sin ningún protocolo, en Boston y Cambridge. Peirce le llamó "el club metafísico". Ignoramos si el "club" estuvo tan organizado como Peirce lo insinúa. Sabemos que se reunían cada quince días en el cuarto de trabajo de Peirce o en el de James. El abuelo del pragmatismo, según confiesa el propio Charles Sanders Peirce, es Bain con su definición de la creencia: "aquello a partir de lo cual el hombre está preparado para actuar".

Para Charles S. Peirce, el único pragmatismo consciente y cabal era el que "recordaba" que "el único bien último que puede estar subordinado a los hechos prácticos a que dirige su atención, es promover el desenvolvi-

6 Charles S. Peirce, Collected Papers of Charles Sanders Peirce, Cambridge, Harvard University Press, 1958, vol. 8, sección 12.

7 Ibid., vol. 1, 175 .

8 Ibid., 6, 610. 
miento de una racionalidad concreta; de tal manera que el significado del concepto no radica en ninguna reacción individual, sino en la manera en que tal reacción contribuye a aquel desenvolvimiento". ${ }^{\circ}$

La gran dificultad que se nos presenta con la teoría de la realidad de Charles S. Peirce proviene de la definición de lo real a través del contexto del conocimiento. Prisionero aún del modernismo - superado por la filosofía contemporánea- cree encontrar la llave del ser en el ser conocido. John E. Smith apunta en su brillante y lúcido libro Themes in American Philosophy, Purpose, Experience of Community, tres críticas capitales a la teoria de Peirce: "I want to suggest thnee critical points at which Peirce's theory shows the limitations of that approach. First, there is the problem of saying precisely what sort of reality is enjoyed by an ultimate opinion that would be, but in fact is not, apprehended by an finite community of knowers; second, thene is the well-known problem of the futurism involved in pragmaticism and in what sense it can allow for presence of the total or unified person or thing; third, thene is the problem of the reality of the several dimensions of things -esthetic, moral, religious, political - that seem to be excluded when the real is defined through the differential and highly abstract medium of theoretical scienoe".10 Pero el valor de la filosofía de Charles S. Peirce no se mide según la porción del quantum de verdad objetiva que contiene, sino por su enorme capacidad de servir como punto de referencia (aunque fuere meramente polémico), para comprenderse a sí mismo y para comprender la realidad. Peirce nos vuelve a despertar del "sueño dogmático"o y nos suscita $e$ inspira la continua búsqueda de la verdad.

\section{El liderato de William James}

William James (1842-1910) ocupa una indiscutible posición de liderato entre los filósofos norteamericanos. Su trayectoria discurre entre viajes a Europa, estudios de pintura y de medicina, enfermedades y crisis espirituales, redacción de libros y conferencias, cátedras de psicología y de filosofía... Se enrola en una expedición al Amazonas y escucha lecciones de filósofos consagrados durante sus años de estancia en Alemania. Obtiene su título de doctor en medicina por la Universidad de Harvard (1869). Tras de sufrir tres años de invalidez física en Cambridge, supera su enfermedad y su crisis espiritual. Empieza su carrera - brillante, fecunda- de profesor universitario en Harvard. Su fama se acrecienta al ser seleccionado para impartir las "Gifford Lectures" en Edinburgh. Publica más de una quincena de libros. Unamuno, Bergson y Papini se expresan elogiosamente de su filosofía. Este background, nada desdeñable, nos muestra a un inquieto,

o Ibid., 5, 2.

10 John E. Smith, Themes in American Philosophy, Harper Row Publishers, New York, Evanston, and London, p. 103. 
osado, inteligente pionero de la filosofía en Estados Unidos que va desde el calvinismo — su padre era un teólogo swedenborgeano- hasta el politeísmo.

Entre la copiosa producción escrita de William James, permítaseme destacar las siguientes obras: The Varieties of Religious Experience: a Study in Human Nature, Pragmatism!: A New Name for Some Old Ways of Thinking: Popular Lectures on Philosophy, The Meaning of Thruth, A Pluralistic Universe: Hibbert Lectures on the Present Situation in Philosophy, Some Problems of Philosophy: A Begining of an Introduction to Philosophy, Essays in Radical Empiricism, The Will to Believe, and Other Essays in Popular Philosophy, Memories and Studies, The Principles of Psychology, Psychology: Briefer Course, Talks to Teachers on Psychology: and to Students on Some of Life's Ideals, Human Inmortality: Two Supposed Objections to the Doctrine.

Fino cultivador del ocio, William James sabía también trabajar duramente en el laboratorio y en la biblioteca. Se esforzó por sobreponerse a la enfermedad y a la desmoralización. Vulgarizó la metodología de su amigo Charles Sanders Peirce y embistió contra los burócratas del mundo y contra los representantes de los ideales y de los principios metafísicos que propiciaban la evasión de la realidad. No andaba lejos de Federico Nietzsche. Como conjuro contra sus numerosos achaques -insomnio, dificultades en la vista, asma de corazón, dolores sordos de espalda, trastornos en el aparato digestivo- levantó el edificio de su filosofía. Escribía con voluntad de crear confianza, con "intención de creer". Observaba, pensaba y publicaba. Filosofaba para mantenerse erguido. "Es preferible - decía- el caos eterno a la disciplina de un cuartel filosófico, aunque el filósofo que la inventó sea el miembro más ilustre de toda la tropa." Los débiles necesitan a Dios, un universo inmutable, unos principios metafísicos; los duros aceptan la libertad, el acaso y lo imprevisible. No hay leyes eternas ni planes fraguados por un honorable legislador filosófico. "La esencia del bien consiste sencillamente en la satisfacción de un deseo." Haya o no haya Dios, vivimos en una sociedad ética. La "persona" en singular es mucho más valiosa e importante que cualquier institución, sociedad o comunidad. La vida es viaje, descubrimiento, sorpresa. "Hay algo nuevo bajo el sol." Naturalista y agnóstico inquieto, William James quiso construir una metafísica que no pecara contra la ciencia. No hay verdad sino verdades. No hay Dios sino dioses. Un pluralismo expansivo y un mundo maleable. "Quien admite lo nuevo tiene que renunciar a toda metafísica." James creía en lo nuevo. Era un agnóstico con una secreta afición por la metafísica y con una aversión innata hacia su propio escepticismo. Dadas estas características, James ha pasado hasta hoy -observa L. Marcuse- "por escéptico contra su voluntad y por creyente sin fe".11 Bajo la apariencia de una docilidad al rumor incesante de los hechos,

11 L. Marcuse, Filosofia americana, Ediciones Guadarrama, Madrid. 
hay en William James un fondo atormentado, trágico. Hasta aquí el temperamento filosófico y la Weltanschauung de William James.

\section{El pragmatismo de William James}

Jorge Luis Borges ha dicho, con aguda y penetrante intuición, que "el praginatismo no quiere coartar o atenuar la riqueza del mundo; quiere ir creciendo como el mundo". ${ }^{12}$ Yo quisiera señalar los límites y las deficiencias de este propósito. Pero antes desearía exponer, en apretado resumen, el pragmatismo de William James.

El actual dilema de la filosofia. La historia de la filosofía es, en grandes líneas, el choque de los caracteres humanos. El rudo (empirista) tiene al delicado (racionalista) como sentimental y dúctil; el delicado piensa que su contrario es duro, empedernido, brutal. El espíritu delicado es racionalista (atenido a los principios), intelectualista, idealista, optimista, religioso, libre arbitrista, monista, dogmático. El espíritu rudo es empirista (se atiene a los hechos), sensacionista, materialista, pesimista, irreligioso, fatalista, pluralista, escéptico. De modo neto y exclusivo, muy pocos hombres son delicados bostonianos o rudos habitantes de las Montañas Rocos̄as. "La filosofía pragmatista, de la que me ocuparé en seguida, guarda también buenas relaciones con los hechos; pero, a diferencia de la filosofía spenceriana, no empieza ni concluye dejando fuera las construcciones religiosas positivas, a las que trata con pareja cordialidad", 13 afirma W. James.

Significado del pragmatismo. El mundo: ¿es uno o múltiple?, ¿libre o predestinado?, ¿material o espiritual? Ante estas magnas cuestiones, el método pragmático interpreta cada noción de acuerdo con sus respectivas consecuencias prácticas. Si las alternativas prácticas tuviesen la misma significación, toda disputa sería vana. "Toda la función de la filosofía - observa William James- debe enderezarse a hallar las diferencias definidas que suscitaría en cada uno de nosotros en momentos determinados en la vida el que resultase cierta esta o aquella fórmula del mundo." 14 Más que soluciones de enigmas, las teorías se convierten en instrumentos. "El pragmatismo conviene con el nominalismo en apelar siempre a los casos particulares; con el uti. litarismo en hacer hincapié sobre los aspectos prácticos; con el positivismo, en su desdén por las soluciones verbales." Aparta los ojos de los principios, categorias, primeras cosas, supuestas necesidades y mira hacia los frutos, las consecuencias, los hechos últimos. Las ideas son verdaderas en la medida que son útiles para entablar relaciones satisfactorias con otros sectores de nuestra

12 Jorge Luis Borges, "Nota Preliminar" a Pragmatismo de William James, Emecé Editores, S. A., Buenos Aires, p. 12.

13 W. James, Pragmatismo, ed. cit., p. 43 .

14 Ibid., p. 51 . 
experiencia. Todo es plástico. El pragmatismo se aviene con los hechos. "Si las ideas teológicas demuestran poseer un valor para la vida concreta, serán verdaderas para el pragmatismo en la medida en que sirvan para ello. En cuanto al resto, su verdad dependerá enteramente de sus relaciones con otras verdades que también han de ser reconocidas." 15 Lo absoluto es una verdad "en tanto que”. Y la verdad es una especie de lo bueno como creencia. “¿Qué podría convenirnos más creer?" Lo que nos conviene es verdadero. Pero una verdad puede entrar en conflicto con otras verdades. Debemos optar por aquellas verdades que mejor se combinen con las demandas de la experiencia.

Algunos problemas metafisicos considerados pragmáticamente. Entre el teísta que afirma la creación del mundo por parte de Dios y el materialista que asegura el resultado del mundo como producto de fuerzas ciegas, el pragmatista asevera que ambas teorías significan lo mismo (el mundo está ya completo) y que la discusión es puramente verbal. Independientemente de la presencia de Dios, la experiencia es lo que es. ¿Existe un plan divino? La palabra "plan", el más estéril de los principios, carece de consecuencias y no explica nada. El libre albedrío carece de significado, a menos que sea una cloctrina de consuelo.

Lo uno y lo múltiple. La filosofía, visión de la unidad del mundo, no puede desconocer la variedad de las cosas. "Pero lo que realmente prefiere nuestro entendimiento no es ni la variedad ni la unidad tomadas aisladamente, sino la totalidad. Aquí -escribe W. James- el conocimiento de las diversidades de la realidad es tan importante como la comprensión de sus conexiones." 16 El mundo es, por lo menos, un objeto para el razonamiento. El espacio y el tiempo son vehículos de continuidad para mantener la cohesión entre las cosas. Todas las cosas se vinculan y adhieren entre sí de algún modo: unidad genérica, unidad de propósito, unión estética. Sin embargo, ningún principio pragmático nos autoriza a reclamar por adelantado la unidad absoluta en ningún respecto. La energía humana fabrica sistemas de conexión. El mundo todavía está imperfectamente unificado. El pragmatismo vuelve la espalda al monismo absoluto y sigue la empírica senda del pluralismo.

El pragmatismo y el sentido comin. "Nuestros modos fundamentales de pensar sobre las cosas - advierte William James- son descubrimientos llevados a cabo por remotos antepasados, que lograron conservarse a través de la experiencia de los tiempos ulteriores." 17 El sentido común es orden en la balumba abigarrada y multiforme de las cosas. Las teorías son modos mentales de adaptación a la realidad.

Concepción de la verdad según el pragmatismo. Para el pragmatismo

15 Ibid., p. $6_{5}$.

16 Ibid., p. 101.

17 Ibid., p. 127. 
"son ideas verdaderas aquellas que podemos asimilar, validar, corroborar y demostrar; ideas falsas, las que no". Tras haber establecido la diferencia práctica que antecede, $\mathrm{W}$. James define: "La verdad de una idea no es una propiedad estancada inherente a ella. La verdad acontece en una idea; ésta se hace verdad; hácenla verdadera los acontecimientos. Su verdad no es sino un hecho, un proceso, el de su propia demostración o verificación; su validez es el proceso de su validación." ${ }^{18}$ Las verificaciones indirectas tanto como las directas son aceptadas. Lo verdadero es sólo el expediente de nuestro modo de pensar.

Pragmatismo y humanismo. "Nuestros aciertos y desaciertos, prohibiciones, castigos, palabras, idiomas, creencias, son otras tantas creaciones nuevas que se van sumando al paso de la historia." 19

Pragmatismo y religión. La utilidad de lo Absoluto ha sido demostrada por todo el curso de la historia religiosa. Trátase de razones vivas, y no.de causas y cosas espectrales. Dejando de hablar oficialmente como pragmatista, William James halla el mundo arriesgado y azaroso sin por esto volverse atrás y gritar "no juego". En el centro mismo de la vida subsiste el hecho negativo. En el fondo de la copia siempre queda algo acerbo y amargo. Hay que conformarse con la posibilidad de que lo esenciado sea dulce. Y concluye aconsejando: "Entre los dos extremos, del crudo naturalismo por una parte, y del absolutismo trascendental por otra, quizás advertiréis que lo que me he permitido denominar tipo pragmatista o meliorista de teísmo es exactamente lo que os conviene." 20

Más allá de mis personales concordancias y divergencias con William James, quisiera destacar su doble carácter de filósofo-psicológico y de psicólogo-filósofo. A los filósofos - como apunta John E. Smith- les enseña a fundamentar el pensamiento en la experiencia y a comprender la experiencia en términos de investigación empírica. A los psicólogos - y a los especialistas en general- les enseña a estar prevenidos críticamente sobre lo que están realizando y a darse cuenta de que su ciencia es un fragmento y un corte de una inmensa realidad que no puede ser ignorada. En su obra The Principles of Psychology (2 vols., New York, Dover Publications, 1950) emplea la introspección - método post mortem que depende de la observación, comparación y uso del lenguaje - sin dejar por ello de utilizar el método experimental. Y es que poséa una rara flexibilidad espiritual que le permitió abordar cuestiones psicológicas sin perder la perspectiva filosófica. 


\section{Empirismo radical y fe religiosa en William James}

La amplitud de las preferencias y tareas de William James puede explicarse, en gran parte, por su estudio del arte y de la ciencia. Temperamento abierto, franco, decidido y tolerante para la diversidad. De la fisiología pasa a la psicología fisiológica, luego a la psicología general, y más tarde a la filosofía.

En psicología, William James acaba con la separación tajante y abismal entre la mente y el cuerpo. La "mente" es la conducta consciente; el "cuerpo" es la contextura biológica en la cual acaece esa conducta. La mente no es materia prima ni sustancia, sino actividad, proceso dinámico.

El "empirismo radical" de W. James es, al mismo tiempo, un postulado, un enunciado de la realidad y una conclusión generalizada. Existan o no las cosas suprasensibles, no se puede sostener una discusión filosófica significativa acerca de ellas. Las significaciones humanas tienen que ser experimentadas. Las relaciones entre las cosas son parte de la experiencia. En el Prefacio a su obra El significado de la verdad escribe: "La enunciación de un hecho consiste en que las relaciones entre las cosas, tanto las copulativas como las disyuntivas, son un asunto de tan particular y directa experiencia, ni más ni menos, como las cosas mismas." $Y$ lineas delante: "El universo directamente aprehendido no necesita, en suma, ningún apoyo extraño metaempirico porque posee en sí mismo una estructura concatenada o continua." 21

La teoría pragmática de la verdad es el paso necesario — según Jamespara la aceptación del empirismo radical. Mientras Peirce se preocupa por las consecuencias generalizadas y habla del significado en términos de un hábito, James se interesa en la consecuencia perceptible particular y considera el significado en términos de usos particulares. Peirce concibe la verdad dependiendo de la verificabilidad pública. James ve en la verdad un nombre genérico que cubre toda clase de valores-directrices en la experiencia. Los valores-directrices están en la experiencia futura y la verdad se torna verdadera. Le interesan los futuros, las consecuencias, las realidades, nunca los principios, categorías, necesidades supuestas. Si una idea puede ser asimilada, corroborada y verificada por los hombres, es verdadera. En el proceso de verificación acontece la verdad. El pragmatismo, al menos el de James, se convierte en practicismo. La utilidad es la función completa de una idea en la experiencia. La verdad vive en un sistema de crédito. Lo verdadero es lo conveniente.

La fe religiosa se justifica, para William James, en la medida que el acrecentamiento de la esperanza y el valor produce consecuencias benéficas en la vida del individuo creyente. Así se justificaría y confirmaría la fe.

21 William James, El significado de la verdad, Editorial Aguilar, Madrid, Buenos Aires, México, p. 37. 
El pensamiento es padre del hecho, pèro el deseo es padre del pensamiento. Hay que distinguir el caso en que ninguna evidencia confirmatoria sea posible, del caso en que el efecto de nuestra creencia pueda alimentar hechos verificadores. En sus conclusiones sobre la vida religiosa, William James advierte: "Summing up in the broadest possible way the characteristics of the religious life, as we have found them, it includes the following beliefs:

"1. That the visible world is part of a more spiritual universe from which it draws its chief significance;

"2. That union or harmonious relation with that higher universe is our true end;

"3. That prayer or inner communion with the spirit thereof - be that spirit 'god' or 'law'- is a process wherein work is really done, and spiritual energy flows in and produces effects, psychological or material, within the phenomenal world.

"Religion includes also the following psychological characteristics;

"4. A new zest which adds itself like a gift to life, and takes the form either of lyrical enchantement or of appeal to earnestness and heroism.

"5. An assurance of safety and a temper of peace, and, in relation to others, a preponderance of loving affections." 22

Ningún hecho en la humana naturaleza es más característico que la voluntad de vivir con oportunidad de salvarse. La existencia de esta oportunidad constituye la diferencia entre una vida cuya clave es la resignación y una vida cuya clave es la esperanza. Dentro de un mundo de almas plurales, no podemos aprobar ni condenar ese mundo como unidad; sólo cabe juzgarlo fragmentariamente. Se da una interpretación de relaciones, no una interdependencia. La realidad es lo que se experimenta como existente. Y el flujo de la experiencia es la conciencia. El orden de la realidad no es más racional que el de la experiencia o el de la conciencia. En sus Ensayos de empirismo radical, William James puntualiza: "Para que un empirismo sea radical no debe admitir dentro de sus construcciones ningún elemento que no sea directamente empírico, ni excluir de ellas ningún elemento que lo sea. Para tal filosofía, las relaciones que conectan las experiencias deben ellas mismas ser relaciones experimentadas y cualquier clase de relación experimentada debe ser considerada tan real como cualquier otra cosa del sistema..." ${ }^{23}$

En su prólogo a la traducción francesa de Pragmatisme, Henri Bergson rincle homenaje a William James en los siguientes términos: "Nadie amó nunca la verdad con amor más ardiente. Nadie la buscó más apasionadamente. Una inmensa inquietud le animaba; y, de ciencia en ciencia, de la anatomía y la fisiología a la psicología, de la psicología a la filosofía, anduvo su

22 William James, The Varieties of Religious, Experience, The Modern Library, New York, p. 475 .

23 William James, Essays in Radical Empiricism, pp. 3, 42-43, 49. 
camino, atento a los grandes problemas, indiferente a todo el resto, olvidándose hasta de sí mismo. Toda su vida la pasó observando, experimentando, meditando. Y como si no hubiera hecho bastante, todavía, a punto de dormir su último sueño, soñaba con experiencias extraordinarias y esfuerzos más que humanos mediante los cuales pudiera, más allá de la muerte, continuar trabajando con nosotros para mayor bien de la ciencia y gloria mayor de la verdad." Aunque estas frases me pueden parecer, como en efecto me parecen, exageradas, coincido con Bergson en que nadie podrá negar a William James su hondura y su originalidad. Todo ello sin mengua de las objeciones y de las reservas que haré a su filosofía al final de mi estudio sobre el pragmatismo norteamericano.

\section{La decisiva impronta de John Dewey}

Muy alejado de "la imperturbabilidad monacal", John Dewey (1859-1952) escribió febrilmente en periódicos y revistas sobre sus impresiones de Rusia en 1928, las tareas de Japón y China en 1920, los catorce puntos de Wilson, la Alemania de la primera Guerra Mundial, el caso León Trotski, la renuncia de Beard a la Universidad de Columbia, la contestación a si mismo de por qué no era comunista... Al final de su casi centenaria vida nos legó una impresionante cantidad de libros, folletos, ensayos largos y artículos cortos. Escribió tratados de ética, estética y teoría del conocimiento. Pero aun en esos tratados, la filosofía fue siempre para él función de la vida cultural de su tiempo. No quiso jamás "dialogar con la eternidad" porque le parecía actitud "medieval" y "romántica". En frase lapidaria de autorretrato nos confiesa: "Yo soy más yanqui y menos filósofo de lo que parece." Le gustaba entrar y salir en todos los ambientes sin ninguna formalidad. Reformó el pragmatismo en medio de las críticas aceradas de sus enemigos. Aunque en un tiempo se autollamó "radical", fue un típico liberal. A los ochenta y siete años se casó por segunda vez y a los ochenta y nueve adoptó a dos niños. Viajó por todo el mundo, hizo suyos todos los problemas de las diversas naciones y quiso apuntar una nueva fe.

"Faith is tendency toward action" (The Question of Certainty, 1919). Para saber lo que una persona cree, es preciso verla actuar. La vieja fe, autoritaria e inmóvil, tiene que ser sustituida por una fe que es "filosofía de la experiencia". Por lo menos, eso es lo que cree Dewey. Esta nueva fe coincide con la era de la industrialización. Cada sociedad se forma un cosmos según su imagen. A la concepción griega del predominio de la ley, la Edad Media añadió la idea de una voluntad superior autoritativa. John Dewey no quiere ser portavoz de lo eterno, sino de lo temporal. ¿Cuál es el futuro de la sociedad industrial? ¿Qué sentido puede tener aún la palabra "filosofía"? El pensamiento de Dewey es una herramienta de derribo. El pensar es como un 
órgano del cuerpo (extremidades o dientes). "Las teorías no son respuestas tranquilizantes a los misterios, sino creaciones que hay que utilizar como instrumentos." Hay, en Dewey, como un retorno al método inventado por Peirce. Los conceptos y las teorías reciben su determinación del desarrollo de sus consecuencias. El pragmatismo clarifica la reflexión a la luz de las consecuencias a que da lugar. El filósofo sirve como "oficial de enlace" entre las diversas áreas de la cultura. Además - cosa primordial para J. Deweyha de cambiar el mundo por obra y gracia de la educación. ¿Hacia dónde? Hacia la creación del individuo libré. Para la transformación del mundo, la metafísica no es necesaria. Las dificultades favorecen el progreso de la raza humana. La filosofía está para aclarar las ideas de los hombres en torno a los fines morales y sociales y a los conflictos de su época. El hombre, animal de costumbres y de afectos, no vive en el tierno regazo de una razón creciente ni está amparado por un plan divino. Hay que laborar el futuro y dotar de sentido a la historia. Todo está en nuestras manos. Se requiere la "colaboración libre de los individuos". Al lado de la libertad para la iniciativa, el espíritu de novedad. El hombre es planificador, constructor, empresario.

De la naturaleza al hombre y del hombre a la sociedad, hay una verdadera continuidad. Ni naturaleza humana innata, ni omnipotencia del medio social. Es preciso buscar el "justo medio". Los hábitos y las tendencias culturales se combinan con las fuerzas de una naturaleza humana común. El medio social puede sofocar, en ocasiones, las fuerzas de una naturaleza humana común, pero la tendencia de esa naturaleza es la de librarse y modificar las instituciones sociales, de modo que formen un medio más libre, más transparente, más propicio a servir a los fines del hombre. La moral es una función de la acción recíproca de estas dos fuerzas. "El reconocimiento inteligente de la concatenación entre la naturaleza, el hombre y la sociedad -advierte John Dewey- es lo único que nos asegura el desarrollo de una moral que será seria sin ser fanática, con aspiraciones pero sin sentimentalismos, adaptada a la realidad sin convencionalismos, sensata sin ser calculadora, e idealita sin ser romántica." 24

La moral interviene en toda actividad en que se presentan otras posibilidades. La cuestión de lo mejor y lo peor sólo se presenta en la acción deliberada, en la élección reflexiva. "El papel de la inteligencia estriba en saber cuándo hay que usar el hecho para conformarse a él y perpetuar las condiciones y consecuencias, y cuándo para modificarlas." 25 En el uso del deseo, de la deliberación y la elección, la libertad se hace real. La moralidad es social. "Hay una vanidad, alimentada por la perversión de la religión, en pretender que el universo se pliegue a nuestros deseos personales; pero también la hay en pretender llevar la carga del universo, de la que la religión

24 John Dewey, Naturaleza humana y conducta, FCE, México, 1964, p. 24.

25 Ibid., p. 271. 
nos libera. Dentro de los actos efímeros e insignificantes de los seres aislados reside un sentido del todo, que los reclama y dignifica. En su presencia nos despojamos de la mortalidad y vivimos en lo universal. La vida de la comunidad en que moramos y en que está nuestro ser es el símbolo adecuado de esta relación. Los actos con que expresamos nuestra percepción de los lazos que nos unen a los demás son sus únicos ritos y ceremonias." 26

La función de los conceptos es práctica. La "psicología" de James sirve a John Dewey como lógica instrumentalista para revolucionar su propia teoria moral. Nada de preceptos, sino deseos reales y activos. Los famosos Studies in Logical Theory (1903) marcan la aparición de "la escuela de Chicago". Las ideas o universales pueden ser ubicadas en la experiencia como planos o hábitos de decisión. La continuidad se da no solamente entre la acción y el juicio, sino también entre el juicio científico y el juicio ético. Las ideas, abstracciones u "objetos lógicos" clarifican actividades confusas en la experiencia. El proceso activo abarca tanto la naturaleza como la experiencia. El espíritu es una clase particular de actividad en un ambiente determinado. Para John Dewey todas las cosas "son realizadas con fines de educación". "La filosofía - -llegó a decir- es la teoría general de la educación." Las artes representarían su práctica general. No hay nada puramente académico acerca de la enseñanza. "Democracia" y "educación" son prácticamente sinónimos. "La democracia es la creencia en la capacidad de la experiencia humana para generar propósitos y métodos por los cuales la experiencia posterior crecerá en una riqueza ordenada." 27 Vivir democráticamente significa, para Dewey, vivir por los principios del empirismo radical.

\section{El instrumentalismo y la cosmovisión de John Dewey}

El pragmatismo tiene muchas variantes y se presta a múltiples desarrollos. Una de esas variantes, que ha adquirido rango y notoriedad en el marco de la filosofía norteamericana y contemporánea, es el "naturalismo experimental" de John Dewey.

La realidad es "todo lo que se encuentra denotativamente". Materia, movimiento, devoción, piedad, amor, belleza y misterio son aspectos reales — no simplemente preferencias arbitrarias o temperamentales- de nuestra experiencia. Yo puedo disfrutar de las cosas o puedo conocerlas. Pero disfrute y conocimiento son "dos dimensiones de las cosas experimentadas". El conocimiento es siempre instrumental. Gobierna y regula la acción. La validez de cualquier idea depende de su funcionamiento, de la prueba experimental. El pensamiento se da en una contextura psicofísica y exige un objeto hacia el

26 Ibid., p. 299 .

27 John Dewey, "Democracia creadora - La tarea que tenemos delante", en The Philosopher of the Common Man, New York, 1940, p. 227. 
cual tiende. Arranca de una situación problemática y se ejerce dentro de la contingencia de la naturaleza. Dewey insiste en el carácter de "genuino azar, contingencia, irregularidad e indecisión" que existe en la naturaleza. No hay estructuras permanentes y fijas, pero se dan dos tipos de cambio: de larga duración (estructura) y de corta duración (proceso). El primero es relativamente estable y permanente; el segundo es más rápido e irregular. Vivimos en un mundo de regularidades e irregularidades. La metafísica queda reducida a una teoría de los rasgos generales de la existencia. Luchamos por la estabilidad.

Ser demócrata es tener fe en la naturaleza humana y en la inteligencia del hombre; fe en el esfuerzo y pensamiento compartido y coordinado en el laboratorio para edificar un mundo mejor. No son palabras textuales de Dewey, pero pudo haberlas dicho en perfecta concordancia con su pensamiento. La comunidad mundial de hombres de ciencia comparte métodos, ideales y código moral.

J. Dewey usó el término de Dios no como principio sobrenatural y causa primera, sino como "relación natural y activa entre lo ideal y lo real".28 Trátase de una existencia realizada en una relación. ¿Cómo hablar legítimamente de "experiencia religiosa" o de "verdad religiosa" bajo estos supuestos?

En su Tearia de la vida moral, John Dewey afirma que "los conceptos y procesos morales nacen naturalmente de las condiciones mismas de la vida humana". Y apunta tres elementos integrantes de la vida moral: 1) El deseo; 2) la vida social (compañerismo, competencia, cooperación, subordinación, demandas, derechos, expectaciones) de cuya acción recíproca de obligaciones y demandas surge el concepto general de ley; 3 ) el bien moral como aquello que probablemente. satisface el deseo. ${ }^{29}$

En su obra El hombre y sus problemas, J. Dewey asegura que la naturaleza humana cambia, sin plantearse el problema ontológico de qué es lo que cambia, cuál es la estructura permanente o quién es el sujeto del cambio. Se nos podrá decir que los problemas ontológicos no le interesan al fundador de la Escuela de Chicago. Pero yo me pregunto si cabe plantearse rigurosamente el cambio de la naturaleza humana sin entrar en el terreno cle la metafísica. John Dewey se limita a decir: "Cuando nuestras ciencias de la naturaleza y de las relaciones humanas se hayan desarrollado aproximadamente como las de la naturaleza física, su interés principal se dirigirá al problema de cómo puede modificarse la naturaleza humana en la forma más efectiva. No se tratará de saber si es susceptible de cambio, sino cómo puede cambiársela en condiciones dadas. Y este problema es, en último aná-

28 J. Dewey, A Common Faith, Yale University Press, 1934, p. $5^{1 .}$

29 John Dewey, Teoria de la vida moral, Herrero Hermanos, Sucs., S. A., México, pp. 203-204. 
lisis, el de la educación en el sentido más vasto de la palabra." 30 ¿Acaso la educación está para cambiar la naturaleza humana y no para llevarla a su plenitud?, podríamos preguntarle a Dewey.

El arte como experiencia es el libro que condensa las reflexiones estéticas de John Dewey. Su propósito fundamental es "recobrar la continuidad de la experiencia estética con los procesos normales de la vida". En el "Prólogo" a la traducción castellana, Samuel Ramos apunta: "Para definir el carácter estético de la experiencia, Dewey emprende el análisis de los fenómenos que constituyen el arte empezando por el acto de expresión... Dewey no advierte que el término expresión significa tanto una acción como un resultado, es decir, que la expresión en el arte no es solamente una actividad de los sujetos que lo producen o que lo gozan, sino además una propiedad inherente a la obra de arte." 31 Para John Dewey el arte es una de las manifestaciones de la interacción arreglada del hombre con su ambiente. Quiero decir que hay un arreglo entre el hombre y el mundo y que este arreglo es, precisamente, el arte. El impulso por reestablecer la armonía es el origen de lo estético. Pero el arte no está separado de la experiencia ordinaria: hay que "restaurar la continuidad entre las formas refinadas e intereses de la experiencia que son las obras de arte, y los acontecimientos, hechos y sufrimientos diarios que se reconocen universalmente como constitutivos de la experiencia". La experiencia estética —que incluye un cuerpo de materias y significados no estéticos por sí mismos- es siempre más que estética. En ella toma el material ampliamente humano un movimiento ordenado y rítmico hacia su consumación. ¡Lástima - y muy grande- que John Dewey nada nos diga sobre lo que es esa consumación! "La experiencia estética —advierte- es una manifestación, un registro y celebración de la vida de una civilización, un medio de promover su desarrollo, y también el juicio último sobre la cualidad de una civilización." 32

Quisiera concluir este breve estudio sobre la filosofía de John Dewey apuntando sus rasgos primordiales: a) Pragmatismo radical contra "el subjetivismo de la filosofía europea"; b) instrumentalidad de la razón; c) experiencia integral de la vida humana como historia; $d$ ) inestabilidad, incertidumbre y problematicidad del mundo; e) lógica como teoría de la investigación ("transformación controlada y dirigida de una situación indeterminada en una situación determinada con sus distinciones y relaciones constitutivas, de manera que convierta los elementos de la situación primitiva en un todo unificado"); f) unidad entre hombre y mundo; g) moralidad como acción recíproca de hábitos y tendencias culturales y fuerzas intrínsecas a una

30 John Dewey, El hombre y sus problemas, Editorial Paidós, p. 171.

31 Samuel Ramos, "Prólogo" a El arte como experiencia, FCE, México, 1949, pp. XII y XIII.

32 John Dewey, El arte como experiencia, ed. cit., p. 288. 
naturaleza humana común; $h$ ) filosofía como crítica de las críticas que pone a prueba el proyecto de vida futura; $i$ ) arte bello como posibilidad de enriquecer el significado de la experiencia y como posibilidad de nuevos y desconocidos gozos.

\section{Critica al pragmatismo norteamericano}

Con el lema positivista de Augusto Comte: "Savoir pour prévoir, prévoir pour pouvoir", se elimina la cuestión de la verdad del conocimiento, para sustituirla por la de su utilidad. Más tarde, el evolucionismo biologizante o, si se prefiere, el biologismo evolucionista desarrolla una teoría vitalista de la verdad. El utilitarismo inglés, por su parte, advertía que una acción será moralmente buena si produce utilidad o placer; mala, si acarrea dolor o perjuicio. Con todos estos antecedentes, nos resulta más fácil comprender el pragmatismo norteamericano.

Aunque el pragmatismo no investigue qué cosas sean verdaderas en sí mismas y qué es la verdad, sino qué frutos se seguirán para la vida práctica, de aceptar como verdaderas o falsas respecto a un punto determinado doctrinas metafísicas opuestas, lo cierto es que subsiste el problema y el tema de la yerdad. Yo puedo cerrar los ojos para no ver un paisaje -clásica actitud del avestruz que esconde la cabeza para no ver el contorno-, pero el paisaje subsiste, no queda eliminado por mi voluntaria ceguera. Antes de preguntarme: ¿qué utilidad o daño para la vida práctica se le seguirá a la humanidad de una estructura monista o pluralista? ¿Qué de la existencia o no existencia de un Dios providente, del libre albedrío, de una vida futura?, habría que saber qué es la utilidad y el daño, qué es la estructura monista o pluralista, qué se entiende por Dios providente, qué es el libre albedrío y qué es la vida futura. Yo me permitiría preguntarle a William James, en caso de que viviese, como podría preguntar sobre lo preguntado sin suponer, en alguna manera, la verdad en sentido ontológico y lógico. La verdad no depende de las consecuencias prácticas que se sigan de dos opiniones opuestas. Las teorías no pueden ser reducidas a simples "instrumentos" al servicio de los hechos o a meros "programas" del trabajo futuro. Rechazando las doctrinas metafísicas, el pragmatismo sustenta un actualismo, un psicologismo y un pluralismo. Pero, ¿cabe rechazar la metafísica para luego caer en otra doctrina metafísica? ¿Podemos quedar satisfechos con una idea de Dios que no sabemos si corresponde o no corresponde a algo real, verdadero, pero que nos sirve para desenvolver y mejorar las condiciones de nuestra vida? ¿Cómo valorizar una determinada religión por el solo hecho de promover el progreso humano? Para todas estas graves cuestiones, el pragmatismo carece de respuestas satisfactorias. Porque juzgar a la religión desde un punto de vista biológico y subjetivo es tanto como confundir las peras con el olmo. 
La verdad de una religión no puede depender exclusivamente de que el hombre se vea estimulado a progresar más. De atenernos al criterio de William James, las religiones serían verdaderas según los hombres y las épocas, puesto que en hombres distintos suelen influir motivos distintos. El tipo pragmatista de teísmo, eficaz para desenvolver la vida y admirablemente adaptado a nuestro tiempo, no puede tomarse como absolutamente verdadero, "porque ignoramos qué concepción de la religión será en lo futuro la más eficaz". ¿Cabe mayor relativismo? Y el relativismo es, a la postre, escepticismo. $Y$ el escepticismo es el suicidio de la filosofía.

El pragmatismo queda reducido, al final de cuentas, a un puro fenomenalismo. Se limita a la experiencia sensible y mutila toda reflexión metafísica. No se contenta con mantenerse neutral frente a la experiencia; eleva a la categoría de máximo dogma la utilidad para el hombre. Y ni siquiera se nos aclara, con pulcritud y rigor, lo que es la utilidad. No está demostrando, tampoco, que el deseo sea siempre la única fuente de nuestros pensamientos. La nivelación de verdad y utilidad es falsa. ¿Qué es lo provechoso y útil? Ningún pragmatista responde satisfactoriamente a esta pregunta. Sustituir el concepto de verdad por el de inquisición, como lo hace Dewey, es caer en una desnuda praxis carente de fundamento.

Proclamar una verdad "práctica", como si fuera la verdad, no es, precisamente una actitud científica. "El pragmatismo - escribe el Prof. Dr. Johannes Hirschberger - es la rebelión del sujeto contra el objeto, una forma moderna de la filosofía del poder y una expresión de la arrogancia del hombre frente a aquello que los griegos decían que es más que el hombre." 33 En tono festivo, Bertrand Russell apunta que la teoría de la verdad, en el pragmatismo, tropieza con serias dificultades. Supongamos que deseamos "responder verídicamente a la simple pregunta de si he tomado yo café o té en rel desayuno. Porque no basta que yo me acuerde de lo que en efecto he hecho esta mañana y a tenor de ello dé mi respuesta, sino que hay que rogar al preguntante un momento de espera, hasta que pueda yo hacer dos experimentos: $1^{\text {9 }}$ qué consecuencias se siguen eventualmente, caso de creer que he tomado café; $2^{\circ}$ cuáles, si creo que he tomado té. Después habrá aún que comparar las dos series de consecuencias posibles. Si una de ellas, por ejemplo la primera, me es más favorable, será verdad que he tomado café. Si no es más favorable, entonces no he tomado café. Si ambas series se equilibran en la balanza, entonces no puedo decidir una cosa ni otra".34 Ingeniosidad aparte, no podemos admitir que el éxito práctico en el mundo sea el criterio de verdad. En buena hora que se busque lo que inspire una conducta eficaz y lo que favorezca la vida; pero que no se altere el sentido de

33 Prof. Dr. Johannes Hirschberger, Historia de la filosofia, Editorial Herder, tomo II, p. 321 . 
la verdad relativizándola. Porque en definitiva estamos hechos para la verdad. Y toda verdad de Dios es y a Dios confluye.

Estados Unidos e Inglaterra son los dos países en donde se ha desarrollado más el pragmatismo. Pero también en Alemania encuentra no escasos partidarios. En varios aspectos, no andan lejos del pragmatismo los empiriocriticistas, Carlos Marx, Georg Simmel y Hans Vaihinger. Tampoco distan mucho del pragmatismo norteamericano los representantes de la "crítica de la ciencia" en Francia (recordemos a Abel Rey).

La reducción de lo verdadero a lo útil admite varias interpretaciones. Para los pragmatistas más radicales, es verdadera la proposición que conduzca a un éxito individual y falsa la que nos lleva a un fracaso. Los pragmatistas más moderados afirman que lo verdadero es lo verificado por los hechos objetivos. De aquí al neopositivismo lógico no hay sino un paso. En términos generales, el pragmatismo consiste, gnoseológicamente, en la negación del conocimiento contemplativo. Estamos en el polo opuesto de la actitud griega clásica, con su primacía de la actividad teorética. La esencia de la verdad reside en la utilidad, el valor, el éxito. No se trata, solamente, de una teoría del conocimiento sino de una filosofía de la vida. Y aunque parezca definitivamente superado, el pragmatismo asoma en la corriente neopositivista y hasta en la existencialista.

Algunos filósofos europeos hablan del pragmatismo norteamericano con visible desprecio y con cierto mal humor. "El origen del pragmatismo -advierte José Ortega y Gasset- habría que buscarlo en el enojo que algunos sienten contra la ciencia, porque no ha demostrado aún la realidad de Dios y la inmortalidad del alma. Por eso llamaron a la ciencia instrumento. Sienten fruición como si al hermano enemigo llamaran raca." 35 Y en otro lugar de sus Obras completas escribe con el desenfado que le es característico: "Según este modo de pensar, no es, pues, la utilidad un precipitado imprevisto y como propina de la verdad, sino al revés: la verdad es el precipitado intelectual de la utilidad práctica. Poco tiempo después, en los albores pueriles de nuestro siglo, se hizo de este pensamiento una filosofía: el pragmatismo. Con el simpático cinismo propio de los yanquis, propio de todo pueblo nuevo - un pueblo nuevo, a poco bien que le vaya, es un enfant terrible-el pragmatismo norteamericano se ha atrevido a proclamar esta tesis: 'No hay más verdad que el buen éxito en el trato con las cosas.' Y con esta tesis tan audaz como ingenua, tan ingenuamente audaz, ha hecho su ingreso en la historia milenaria de la filosofía el lóbulo norte del continente americano." 36 Y después de haber trazado el origen y los rasgos esenciales del prag. matismo, el filósofo español apunta su error primordial. Oigámosle: "El

35 José Ortega y Gasset, Obras completas, Editorial Revista de Occidente, Madrid, vol. I, p. 119 .

36 Ibid., vol. IV, p. 97 . 
error del pragmatismo no radica en que considere las ideas como instrumentos, sino en que quiera reducir las cosas con que el hombre tiene que habérselas a lo perceptible y experimentable, lo que está a la mano y presente, el mineral, la planta, el animal y la estrella. (Porque la estrella por muy lejos que esté está siempre también a la mano.) Si así fuese, la vida resultaría faena fácil, tal vez resuelta con cierta plenitud hace milenios." 37

Alfredo Fouillée embiste contra el pragmatismo norteamericano en términos poco comedidos: "Durante estos últimos años hemos presenciado el desarrollo de su sistema anti-intelectualista $\dot{y}$ neo-sofístico que ha tomado el nombre de pragmatismo. Consiste en una filosofía esmpírica de la acción y del hecho (to pragma) que reduce el conocimiento a una acción eficaz y la verdad a la utilidad para la vida o para la acción. En esta filosofía que es una exageración y una deformación de las ideas-fuerzas, la fuerza de las ideas es lo que constituye su verdad, mientras que, para la doctrina de las ideas-fuerzas, es la verdad de las ideas o su conformidad con las relaciones reales de las cosas lo que constituye su misma fuerza. El pragmatismo, sostenido principalmente en América por el psicólogo William James, es un causa-finalismo retrógrado que juzga el valor de las doctrinas por sus consecuencias y por su comodidad para los fines humanos. Como en la doctrina de Protágoras, es el hombre lo que constituye la medida de todas las cosas." 3s

José Vasconcelos se muestra más comprensivo con el pragmatismo. Y lo sitúa, con verdadera penetración, en su ambiente histórico. "Walt Whitman, un poeta, y Ralf Waldo Emerson, un ensayista, son los precursores de la filosofía norteamericana. En ellos busca formas mentales el temperamento del pioneer, prototipo de la raza victoriosa sobre el continente nuevo. El optimismo es la nota dominante de la nueva doctrina y cierta generosidad que abre a todos los hombres los caminos y las praderas de la tierra recién hallada: Pero como no es tierra de abundancia natural, sino una que es menester trabajar, laborar, junto al júbilo de la conquista vendrá la advertencia de poner el ingenio en la obra. No se trata, pues, de un credo contemplativo, como el que parece obligado en las mesetas estériles del Tibet, sino un credo de acción. La doctrina estaba difusa en la literatura, hasta que se formó en Harvard el grupo que presidieron Carlos Sanders Peirce y Guillermo James, a principios del siglo.

"En rigor, el pragmatismo es un eco del viejo utilitarismo inglés y una extensión nacional del buen sentido común de Robinson Crusoe." 39 Y tras la descripción impresionista del pragmatismo, Vasconcelos analiza el practicismo de Peirce, la filosofía del éxito de William James, que entronca con el

37 Ibid., vol. IV, pp. $357-355^{8}$.

38 Alfredo Fouillée, Historia general de la filosofí, Ed. Nueva Biblioteca Filosófica, Madrid, 1933, vol. IV, p. $15^{6}$.

39 José Vasconcelos, Historia del pensamiento filosófico, Ediciones de la Universidad Nacional Autónoma de México, 1937, p. 435. 
darwinismo y el instrumentalismo de Dewey ("la verdad se logra haciendo", "controlar el mundo es el problema de la filosofía"). Espera, nuestro "Ulises criollo", que otra filosofía tendrá que salir de la nueva experiencia norteamericana. He aquí su conclusión final: "Lo más curioso del pragmatismo es que creyéndose nuevo, no era otra cosa que regresión a la edad primitiva de la mente, cuando aún el problema del significado del hecho, en relación con el pensamiento que lo contempla, no puede plantearse." 40

Me parece que por utilidad, tal como la apunta James, no hay que entender tan sólo las necesidades materiales del individuo sino toda aquello que favorezca el despliegue del hombre y el desarrollo de la sociedad. Bajo esta luz es como hay que comprender a la religión como una hipótesis fecunda. Y aunque he apuntado ya mis divergencias con el pragmatismo norteamericano, no dejo de advertir - y de valorar - el noble propósito de acercar la filosofía y la vida, el pensamiento y la acción. Pero mi concepto de la verdad, ${ }^{41}$ menester es decirlo, es radicalmente diverso del que sustentan los pragmatistas norteamericanos.

Hasta aquí el estudio del pragmatismo norteamericano que, aunque no es la única filosofía forjada en los Estados Unidos, resulta la más representativa.

Agustín Basave Fernández del Valle

Centro de Estudios Humanísticos de la

Universidad Autónoma de Nuevo León

40 Ibid., p. 437 .

41 Véase mi estudio "Fundamento y esencia de la verdad", Anuario Humanitas 1968, Centro de Estudios Humanísticos de la U.A.N.L. 